\title{
PTC209, a Specific Inhibitor of BMI1, Promotes Cell Cycle Arrest and Apoptosis in Cervical Cancer Cell Lines
}

\author{
JUNAN LI ${ }^{1,2, *}$, ZACHARY VANGUNDY ${ }^{2,3}$ and MING POI ${ }^{1,2,3}$ \\ ${ }^{1}$ Division of Pharmacy Practice and Administration, College of Pharmacy, \\ The Ohio State University, Columbus, OH, U.S.A, \\ ${ }^{2}$ Comprehensive Cancer Center, The Ohio State University, Columbus, OH, U.S.A; \\ ${ }^{3}$ Department of Pharmacy, The Arthur G. James Cancer Hospital and \\ Richard J. Solove Research Institute, Columbus, OH, U.S.A.
}

\begin{abstract}
Background/Aim: Aberrant expression of the BMII oncogene has been prevalently found in a variety of human cancers, including cervical cancer. Recent studies have shown that PTC209, a specific BMII inhibitor, exhibits high potency in inhibiting the growth of colon, breast, oral cancer cells and cancer-initiating cells, indicative of its chemotherapeutic potential. In the current study, we evaluated the inhibitory abilities of PTC209 in cervical cancer cells. Materials and Methods: Three cervical cell lines, C33A, HeLa, and SiHa were treated with PTC209. The impacts of PTC209 on BMII were investigated using quantitative reverse-transcription $P C R$ assay (qRT-PCR) and western blotting; changes in cell viability, cell cycle distribution, and apoptosis were assessed using cell viability testing, colony formation assay and flow cytometry analyses, respectively. Results: PTC209 exhibited considerably high short-term and long-term cytotoxicities in all tested cervical cancer cell lines regardless of their HPV infection status, TP53 and pRb statuses. PTC209 significantly downregulated the expression of BMII in cervical cancer cell lines, and such downregulation led to G0/G1 arrest $(p<0.05)$. Moreover, PTC209 drove more cells into apoptosis $(p<0.05)$. Conclusion: PTC209 (BMI1-targeting agents, in general) represents a novel chemotherapeutic agent with potential in cervical cancer therapy.
\end{abstract}

Cervical cancer is the fourth most common malignancy affecting women worldwide with an ascending incidence and youthful trends in developing countries, and about 250,000 deaths have been estimated annually $(1,2)$. In the United

Correspondence to: Dr. Junan Li, College of Pharmacy, The Ohio State University, Columbus, OH 43210, USA. Tel: +1 6242921036 , Fax: +16142922588, e-mail: li.225@osu.edu.

Key Words: PTC209, BMI1, inhibition, cervical cancer, cancer stem cell.
States, more than 13,000 women will be newly diagnosed with cervical cancer and about 4,200 women will die from this malignancy in 2019 (1). Since human papillomavirus (HPV) is found in about $99 \%$ of cervical cancers, the etiology of cervical cancer has been widely recognized as a result of HPV infection $(3,4)$. However, it is known that HPV infection alone is not sufficient to generate a fully malignant phenotype (5). The molecular mechanisms underlying the malignant transformation and progression of cervical cancer remain poorly understood (6-8).

Recent studies have shown that polycomb complex protein B-lymphoma Mo-MLV insertion region 1 (BMI1) is associated with the development and progression of a variety of human cancers, including colon, oral, breast, ovarian, endometrial, biliary tract, liver, gastric, prostate, pancreatic, and lung and cervical cancer (9-14). BMI1 is a key protein partner in polycomb repressive complex 1 (PRC1) that represses gene transcription by mono-ubiquitylation of histone 2A at Lys 119 (H2AK119ub) $(11,12,15,16)$, and it impacts gene expression pattern involved in cell proliferation, growth, DNA repair, apoptosis, and senescence $(9,15,16)$. Aberrant expression of BMI1 at the mRNA or protein level has been prevalently found in human cancers, and correlates with advanced disease stages, aggressive clinicopathological behavior, poor prognosis, and resistance to radiation and chemotherapy $(5,9,14,16-22)$. Therefore, BMI1 is emerging as a potential chemotherapeutic target in cancer therapy. A low-molecular-weight compound, PTC209 (Figure 1A) has been found to be able to downregulate the expression of BMII in a number of breast, colon, prostate, and biliary tract cancer cells and cancer-initiating cells, resulting in inhibition of cell proliferation, induction of apoptosis and/or senescence, increased susceptibility to cytotoxic agents and radiation therapy, inhibition of epithelial mesenchymal transition (EMT) and cancer stemness $(15,23-31)$. In regard to the fact that aberrant $B M I I$ expression is prevalent in cervical cancer patients, we 
hypothesized that PTC209 would exhibit inhibitory potency in cervical cancer cells. In this study, we evaluated the impact of PTC209 on cell proliferation and apoptosis in cervical cancer cells. Our results showed that PTC209 exhibited considerable cytotoxicity in three tested cervical cancer cell lines, C33A, HeLa, and SiHa. PTC209 significantly downregulated $B M I 1$ expression in these cells, resulting in $\mathrm{G}_{0} / \mathrm{G}_{1}$ arrest and apoptosis. Our results support further studies on PTC209 as a novel chemotherapeutic agent in cervical cancer therapy.

\section{Materials and Methods}

Cell lines and reagents. Three cervical cancer cell lines, C33A, $\mathrm{HeLa}$, and $\mathrm{SiHa}$ were purchased from the American Type Culture Collection (ATCC, Manassas, VA, USA). The characteristics of these cervical cell lines are summarized in Table I. All cell lines were maintained in advanced Dulbecco modified Eagle medium (DMEM) medium (Life Technologies Corporate, Carlsbad, CA, USA) supplemented with 5\% fetal bovine serum (FBS; Life Technologies), $1 \%$ glutamine (Life Technologies), $1 \%$ penicillin/streptomycin (Life Technologies) at $37^{\circ} \mathrm{C}$, in a humidified atmosphere with $5 \% \mathrm{CO}_{2}$. These cell lines were regularly authenticated using short tandem repeat polymorphism (STRP) analysis as recommended by ATCC, and they were mycoplasma free. Cells were grown up to passage 20 . PTC209 (CAS 315704-66-6; Figure 1A) was purchased from SigmaAldrich ((St. Louis, MO, USA).

Gene expression assay. Cells were seeded at $1 \times 10^{6}$ cells/T25 flask (Life technologies) and incubated in DMEM-5\% FBS media overnight. Cells were then incubated with media containing PTC209 at indicated concentrations $(0 \mu \mathrm{M}, 1 \mu \mathrm{M}, 2 \mu \mathrm{M}, 5 \mu \mathrm{M}$, and $10 \mu \mathrm{M}$;) at $37^{\circ} \mathrm{C}$ and $5 \% \mathrm{CO}_{2}$ for another $24 \mathrm{~h}$. Cells were harvested by trypsin and centrifugation and total RNA was purified using a RNeasy Purification kit (Qiagen, Valencia, CA, USA). cDNAs were synthesized using a High Capacity cDNA Reverse Transcription kit (Life Technologies). The expression levels of target genes were quantitatively assessed using Taqman ${ }^{\circledR}$ gene expression assays (Life Technologies) using the following inventoried primer/probes: Hs00409825_g1 for BMI1, and Hs99999909_m1 for human hypoxanthine phosphoribosyltransferase (HPRT1). Of note, HPRT1 was used as an endogenous reference for normalized gene expression. PTC209 treatment experiments were performed in triplicate. For each cDNA sample, target genes were amplified separately, and expression quantitation assays were performed in triplicate. The relative gene expression level (REL) of BMI1 (in comparison with $H P R T 1$ ) was determined using a comparative $\mathrm{Cq}$ method in which REL was defined as $2^{-\delta C q}(32)$.

Western blot. Cell pellets were washed three times in ice-cold PBS (phosphate saline, pH 7.4) and then lysed with RIPA buffer [20 mM Tris-HCl (pH 7.5), $150 \mathrm{mM} \mathrm{NaCl}, 1 \mathrm{mM} \mathrm{Na} 2$ EDTA, 1mM EGTA, $1 \%$ NP-40, $1 \%$ sodium deoxycholate, $2.5 \mathrm{mM}$ sodium pyrophosphate, 1 $\mathrm{mM} \beta$-glycerophosphate, $1 \mathrm{mM} \mathrm{Na} \mathrm{VO}_{4}, 1 \mathrm{mM}$ PMSF, and $1 \mu \mathrm{g} / \mathrm{ml}$ of leupeptin; Cell Signaling Technology, Beverly, MA, USA] on ice for $20 \mathrm{~min}$. Subsequently, cell lysates were clarified by centrifugation at $4^{\circ} \mathrm{C}, 13,000 \mathrm{rpm}$ for $5 \mathrm{~min}$ and the concentration of total proteins in the supernatants was determined using the BCA assay (Thermo Fisher Scientific). The samples were subjected to SDS-PAGE (10\%
A<smiles>COc1cc(Br)c(Nc2nc(-c3c(C)nc4ncccn34)cs2)c(Br)c1</smiles>

PTC 209

$\mathrm{N}-(2,6-$ Dibromo-4-methoxyphenyI)-4-(2methylimidazo[1,2-a]pyrimidin-3-yl)-2-thiazolamine

B

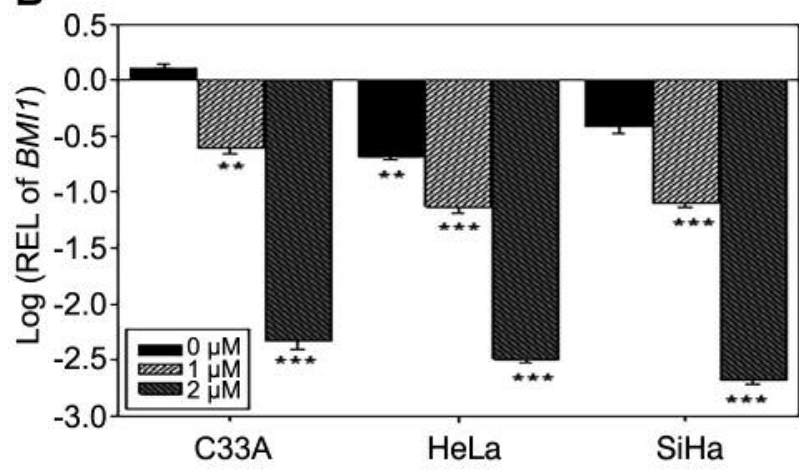

C

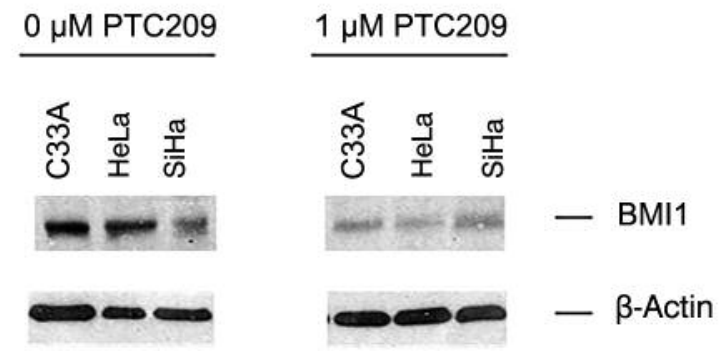

Figure 1. PTC209 downregulated the expression of BMI1 in cervical cancer cells. A) The chemical structure of PTC209. B) The expression of BMII mRNA in cervical cancer cells decreased in the presence of PTC209. Pre-validated qRT-PCR-based assays were used to evaluate the mRNA expression levels of target genes. While HPRT1 was used as an endogenous reference for gene expression, cells without PTC209 treatment were used as controls. The relative expression level of BMII $m R N A$ was defined using the $2^{-\delta C q}$ method. PTC209 treatment experiments were performed in triplicate. Each expression quantitation assay was repeated at least three times. Data are presented as mean \pm standard deviation. For each cell line, group-wise comparisons were between the groups with PTC209 at indicated concentrations (1 $\mu M$ and $2 \mu M)$ and the group without PTC209 treatment $(0 \mu M)$. $* p<0.05 ; * * p<0.01 ; * * * p<0.001$. C) Western blot analysis of BMI1 protein. Samples containing $50 \mu \mathrm{g}$ of total soluble proteins per lane were subjected to SDS-PAGE for separation, and transferred to nitrocellulose membrane followed by immunoblotting using following antibodies: mouse anti-BMI1 monoclonal antibody (sc-390443, Santa Cruz Biotechnology, Dallas, TX, USA), mouse anti- $\beta$ actin monoclonal antibody (sc-56459, Santa Cruz Biotechnology), rabbit anti-mouse IgG $(H+L)$ secondary antibody conjugated with horse radish peroxidase (HRP) (A16160, Thermo Fisher Scientific). $\beta$-Actin was used as an endogenous control. 
Table I. Characteristics of cervical cancer cell lines*.

\begin{tabular}{lccc}
\hline Cell & Morphology & Origin & Molecular characteristics \\
\hline C33A & Epithelial & Cervical adenocarcinoma & HPV16-negative, HPV18-negative; p53+, highly expressed, R273C; \\
pRb+, abnormal in size.
\end{tabular}

*Information from American Type Culture Collection (www.atcc.org)

or $15 \%$ ) at $50 \mu \mathrm{g}$ of total proteins per lane and then transferred to a nitrocellulose membrane and immunoblotted with the following antibodies: mouse anti-BMI1 monoclonal antibody (sc-390443, Santa Cruz Biotechnology, Dallas, TX, USA), mouse anti- $\beta$ actin monoclonal antibody (sc-56459, Santa Cruz Biotechnology), rabbit anti-mouse $\operatorname{IgG}(\mathrm{H}+\mathrm{L})$ secondary antibody conjugated with horse radish peroxidase (HRP) (A16160, Thermo Fisher Scientific). The concentration of each antibody was used as suggested by the suppliers. Immunodetection was performed using the enhanced chemiluminescence (ECL) kit (Thermo Fisher Scientific) (33).

Cell viability assay. Cells were seeded at 2000 cells/well in $100 \mu \mathrm{l}$ of advanced DMEM- 5\% FBS media and incubated at $37^{\circ} \mathrm{C}$ and $5 \%$ $\mathrm{CO}_{2}$ overnight. Subsequently, cells were incubated with media containing various concentrations of PTC209 for another $24 \mathrm{~h}$. Cell viability was assayed using WST-1 Cell proliferation Assay kit (Roche, Indianapolis, IN, USA) following the manufacturer's directions. Assays were performed in triplicate at least twice. Absolute $\mathrm{IC}_{50}$ values (the concentration of cisplatin required to inhibit $50 \%$ of the cell viability) were determined using Kaleidagraph software (Synergy Software, Reading, PA, USA) as previously described (34).

Colony formation assay. Cells were seeded in 12-well plates at 5001,000 cells/well and grown at $37^{\circ} \mathrm{C}$ and $5 \% \mathrm{CO}_{2}$ for $24 \mathrm{~h}$. Cells were then treated with PTC209 at indicated concentrations for 7-10 days. Growth media were changed with or without drugs every other day. When the colony could be seen by naked eyes, the culture was terminated. After removal of the media, cells were washed with PBS, fixed with $4 \%$ paraformaldehyde for $15 \mathrm{~m}$, and stained with a $0.5 \%$ crystal violet solution for 2-4 h. Plates were washed with tap water to excessive staining solution. The colonies were counted and photographed $(35,36)$. Three duplicates were set up in each group, and each reaction was run in triplicate. The colony formation ability was defined as the number of colonies at the indicated concentration of PTC209/the number of colonies without PTC209×100\%.

Flow cytometry for cell cycle distribution. After PTC209 treatment for $24 \mathrm{~h}$, cells $\left(1 \times 10^{6}\right)$ were collected by trypsin and centrifugation and washed with pre-cold PBS. Subsequently, cells were fixed in $70 \%$ ethanol at $4^{\circ} \mathrm{C}$ for $12 \mathrm{~h}$, followed by incubation in $50 \mu \mathrm{g} / \mathrm{ml}$ RNase A solution (BD Biosciences, San Jose, CA, USA) at $37^{\circ} \mathrm{C}$ for $30 \mathrm{~min}$. Samples were incubated with $10 \mathrm{~g} / \mathrm{ml}$ propidium iodide (BD Biosciences) in the dark for $15 \mathrm{~m}$, and then analyzed by Attune NxT flow cytometer (Thermo Fisher Scientific, Rockford, IL, USA) (35). Each treatment was conducted in triplicate, and each sample was analyzed at least twice.
Flow cytometry for apoptosis. After treatment with PTC209 at indicated concentrations for $24 \mathrm{~h}$, cells $\left(1 \times 10^{6}\right)$ were collected and stained with FITC Annexin-V/PI Apoptosis Detection kit I (BD Biosciences) following the manufacturer's instructions. Cells were subjected to Attune NxT flow cytometer (Thermo Fisher Scientific) to measure apoptosis (37). Each treatment was conducted in triplicate, and each sample was analyzed at least twice.

Statistical analyses. R3.4 (R: The R Project for Statistical Computing, https://www.r-project.org) was used in this study. Measurement data were presented as mean \pm standard deviation (SD). Group-wise comparisons were analyzed using Student's $t$-tests, and no multiple comparison adjustment was applied. Of note, gene expression data were subjected to log transformation to fulfill the normality requirement prior to group-wise comparison. All tests were two-sided and the significance level was preset at $\alpha=0.05$. $* p<0.05 ; * * p<0.01 ; * * * p<0.001$.

\section{Results}

PTC209 potently downregulated the expression of BMII in cervical cancer cells. It has been reported that PTC209 specifically decreases BMI1 at the transcription and/or protein level in a variety of cancer cell lines and patientderived cancer cells, whereas the underlying molecular mechanisms remain to be further elucidated. In the present study, we first evaluated the impacts of PTC209 on BMI1 in three cervical cancer cell lines, C33A, HeLa, and SiHa. These three cell lines were selected for the following reasons: while HPV infection is found in almost all cervical cancer specimens (>99\%), HPV16 and HPV18 are the two major high-risk HPV types that may cause cervical cell abnormalities or cancer, and more than $70 \%$ of cervical cancer cases can be ascribed to HPV16 and HPV18 $(3,4)$. In the meanwhile, abnormalities in tumor suppressive TP53 and $p R b$ genes are the most prominent genetic alterations found in human cancers $(32,38)$. As summarized in Table I, C33A, HeLa, and SiHa have different molecular characteristics, which jointly may represent the wide scope of cervical cancer cells.

In the absence of PTC209, the baseline expression levels of BMI1 mRNA varied considerably among these three cells (Figure 1B). While HeLa and SiHa had comparable baseline 
expression levels of BMII mRNA $(p>0.05)$, the baseline expression level of BMII mRNA in C33A appeared to be relatively high ( $p$-values $<0.05$ in comparison with HeLa or $\mathrm{SiHa}$. Interestingly, PTC209 downregulated the expression of BMII mRNA in all three cell lines. After a 24-h incubation, $1 \mu \mathrm{M}$ PTC209 reduced the expression of BMII mRNA by 5 -10-fold in these cell lines (all $p$-values $<0.01$ ). Two $\mu$ M PTC209 brought about more than 100-fold decrease in $B M I 1$ mRNA expression (all $p$-values $<0.001$ ), whereas the expression of BMII mRNA was undetectable in these cells with high concentrations of PTC209 $(5 \mu \mathrm{M}$ and $10 \mu \mathrm{M}$, data not shown). These observations were further supported by immunoblotting analyses of BMI1 protein in these cells. As shown in Figure 1C, the baseline levels of BMI1 protein in these three cell lines appeared to be different, and $1 \mu \mathrm{M}$ PTC209 decreased the level of BMI1 protein in all three cell lines. Of note, BMI1 protein was undetectable in all three cell lines with higher concentrations of PTC209 ( $2 \mu \mathrm{M}, 5$ $\mu \mathrm{M}$ and $10 \mu \mathrm{M}$, data not shown). With regard to the different characteristics of these three cell lines (Table I), these results indicate that PTC209 is a potent inhibitor that downregulates BMI1 in cervical cancer cells regardless of HPV infection and genetic statuses of TP53 and $p R b$.

PTC209 inhibited the growth of cervical cancer cells. We then evaluated the cytotoxicity of PTC209 in these cervical cancer cells. Results from cell viability assays demonstrated that PTC209 exhibited considerable inhibitory activity in these cells after $24 \mathrm{~h}$ treatment. The $\mathrm{IC}_{50}$ values of PTC209, i.e. the concentrations required to inhibit $50 \%$ of cell viability, were $12.4 \pm 3.0 \mu \mathrm{M}, 4.3 \pm 1.8 \mu \mathrm{M}$, and $21.6 \pm 4.2 \mu \mathrm{M}$ in C33A, HeLa, and $\mathrm{SiHa}$, respectively (Figure 2A). HeLa appeared to be more sensitive to short term ( $24 \mathrm{~h})$ treatment with PTC209 as evidenced by an $\mathrm{IC}_{50}$ value lower than that of C33A (by 3-fold) or $\mathrm{SiHa}$ (by 5-fold). Further, colony formation assays showed that PTC209 exhibited very high long-term (up to 7 days) cytotoxicity as evidenced by the fact that $2 \mu \mathrm{M}$ PTC209 inhibited the colony formation abilities of these cells by more than $50 \%$ (Figure 2B). While only remnant colony formation abilities were observed in C33A and SiHa in the presence of $5 \mu \mathrm{M}$ PTC209, HeLa retained about $35 \%$ and $20 \%$ of colony formation ability in the presence of $5 \mu \mathrm{M}$ and $10 \mu \mathrm{M}$ PTC209, respectively, implying that HeLa might be less sensitive to PTC209 after long term treatment than $\mathrm{C} 33 \mathrm{~A}$ or $\mathrm{SiHa}$. Apparently, this observation is different to a certain extent from our previous results showing that HeLa was more sensitive to PTC209 after short term treatment. The mechanisms underlying such "disparity" between short- and long-term cytotoxicities of PTC209 in HeLa remain to be further explored.

PTC209 induced $G_{0} / G_{1}$ arrest and apoptosis in cervical cancer cells. Subsequently, we investigated the potential impact(s) of
PTC209 in the cell cycle progression of these cells. Flow cytometry analyses showed that with $24 \mathrm{~h}$ incubation, there was a statistically significant increase in the number of cells at the $\mathrm{G}_{0} / \mathrm{G}_{1}$ phase upon PTC209 treatment $(5 \mu \mathrm{M}$ and $10 \mu \mathrm{M})$ compared to the untreated cells (all $p$-values $<0.05$ ) (Figure 3). The proportion of cells in the $\mathrm{G}_{0} / \mathrm{G}_{1}$ phase increased from $57.9 \%(0 \mu \mathrm{M})$ to $64.7 \%(5 \mu \mathrm{M})$ and $64.1 \%(10 \mu \mathrm{M})$ in $\mathrm{C} 33 \mathrm{~A}$, from $53.2 \%(0 \mu \mathrm{M})$ to $60.4 \%(5 \mu \mathrm{M})$ and $63.9 \%(10 \mu \mathrm{M})$ in HeLa, from $61.3 \%$ to $68.3 \%$, and $67.2 \%$ in SiHa. Accordingly, numbers of cells in the $S$ phase and/or the $G_{2} / M$ phase decreased upon PTC209 treatment.

Lastly, we examined the apoptotic effect of PTC209 in these cells using annexin $\mathrm{V}$ and propidium (PI) staining followed by flow cytometry analyses. Our results demonstrated that after treatment for $24 \mathrm{~h}$, PTC209 significantly increased total apoptosis (annexin $\mathrm{V}^{+} / \mathrm{PI}^{-}$and annexin $\mathrm{V}^{+} / \mathrm{PI}^{+}$) in these tested cells in a concentration-dependent manner (Figure 4). After 24 h treatment with PTC209, about 6.6\% (5 $\mu \mathrm{M})$ and 10.5\% (10 $\mu \mathrm{M})$ of C33A cells underwent apoptosis compared to $3.5 \%$ in untreated C33A cells (0 $\mu \mathrm{M})$. Similarly, PTC209 treatment increased the numbers of HeLa apoptotic cells from $10.3 \%$ (0 $\mu \mathrm{M})$ to $19.2 \%(5 \mu \mathrm{M})$ and $34.1 \%(10 \mu \mathrm{M})$. For SiHa cells, about $4.3 \%$ cells underwent apoptosis without PTC209 treatment, and such percentages increased to $8.1 \%$ and $15.4 \%$ upon treatments with $5 \mu \mathrm{M}$ and $10 \mu \mathrm{M}$ PTC209, respectively. Interestingly, in $10 \mu \mathrm{M}$ PTC209-treated HeLa cells, about 30\% cells were in the early apoptotic stage (annexin $\mathrm{V}^{+} / \mathrm{PI}^{-}$) and $4.1 \%$ cells were in the late apoptotic stage (annexin $\mathrm{V}^{+} / \mathrm{PI}^{+}$). In comparison, about $5.5 \%$ and $10.0 \%$ of $10 \mu \mathrm{M}$ PTC209treated SiHa cells were in early apoptosis and late apoptosis, respectively. As for $10 \mu \mathrm{M}$ PTC209-treated C33A cells, the proportions of cells in early apoptosis and late apoptosis were about $5.8 \%$ and $4.7 \%$, respectively.

\section{Discussion}

PcG-mediated transcriptional repression provides universal mechanisms to modulate genes involved in embryonic development, cell proliferation and apoptosis, maintenance of cellular identity, and aberrant functioning of PcG complexes has been shown to correlate with diverse human cancers (9, 15). PcG proteins assemble into multi-component complexes that remodel local chromatin structure both directly and through the establishment and removal of post-translational modifications of histone proteins, thus influencing the accessibility of target genes to transcription factors. One major PcG complex, PRC1, specifically monoubiquitylates histone Lys 119 through its ubiquitin E3 ligase activity, and consequently silences a number of target genes, one of which is the INK4a-ARF gene $(11,16)$. The INK4a-ARF gene encodes p16INK4A and p14ARF proteins, which negatively regulate the prominent CDK4-pRb pathway and the MDM2p53 pathways, respectively (38). Hence, as an essential 

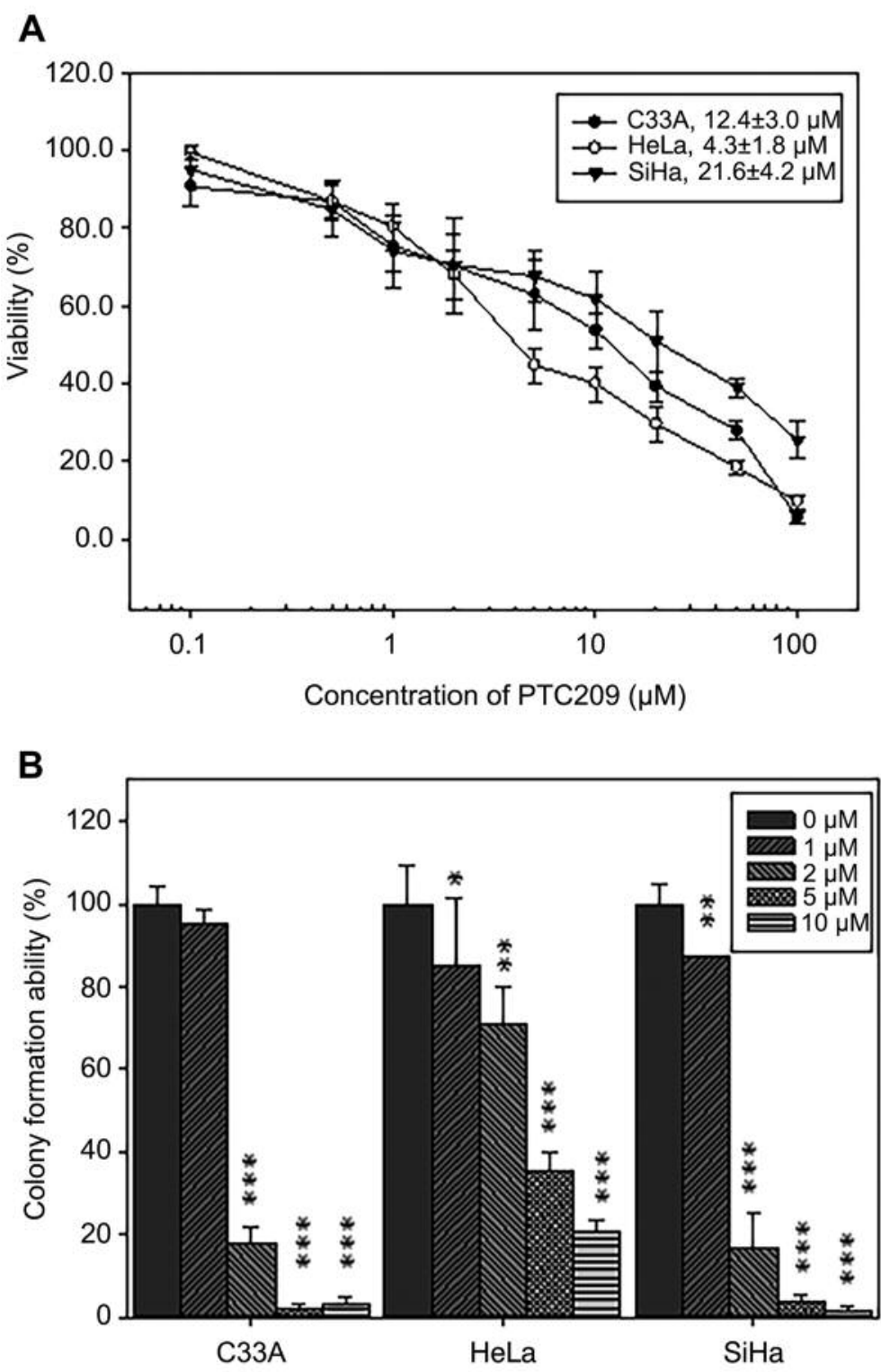

Figure 2. PTC209 inhibited the growth of cervical cancer cells. A) Short-term cytotoxicity. Cervical cancer cells were incubated with various concentrations of PTC209 for $24 \mathrm{~h}$. Cell viabilities were then evaluated using WST-1 cell proliferation Assay kit following the manufacturer's instruction, and $I C_{50}$ values, the concentrations of cisplatin required to inhibit 50\% of the cell viability, were calculated using a 4-parameter nonlinear regression approach. Experiments were conducted at least in triplicate. B) Long-term cytotoxicity. Cervical cancer cells were plated in 12well pates (about 500 cells/well) and incubated in regular media for 24 h followed by media containing indicated concentrations of PTC209 (0, 1 , 2, 5, and $10 \mu \mathrm{M})$ for another 7 days. After fixation with 4\% paraformaldehyde, cells were visualized under a microscope. Three duplicates were set up in each group, and each reaction was run in triplicate. The colony formation ability was defined as the number of colonies at the indicated concentration of PTC209/the number of colonies without PTC209×100\%.

component of PRC1, BMI1 is involved in the regulation of pRb-mediated cell cycle control and p53-mediated apoptosis as well as other related cellular process $(9,38,39)$. It is no wonder that BMI1 deregulation (such as aberrant expression of BMII) has been clearly implicated in the tumorigenesis and development of many human cancers (9-14). Here, we reported that PTC209-mediated downregulation of BMI1 in cervical cancer cells induced $G_{0} / G_{1}$ arrest and apoptosis, thus exhibiting considerably high short-term and long-term cytotoxcities. Our results are consistent with previous studies showing that PTC209 treatment led to cell cycle arrest and apoptosis in many cancer cells in vitro and in vivo (23-31), 


\section{A C33A}

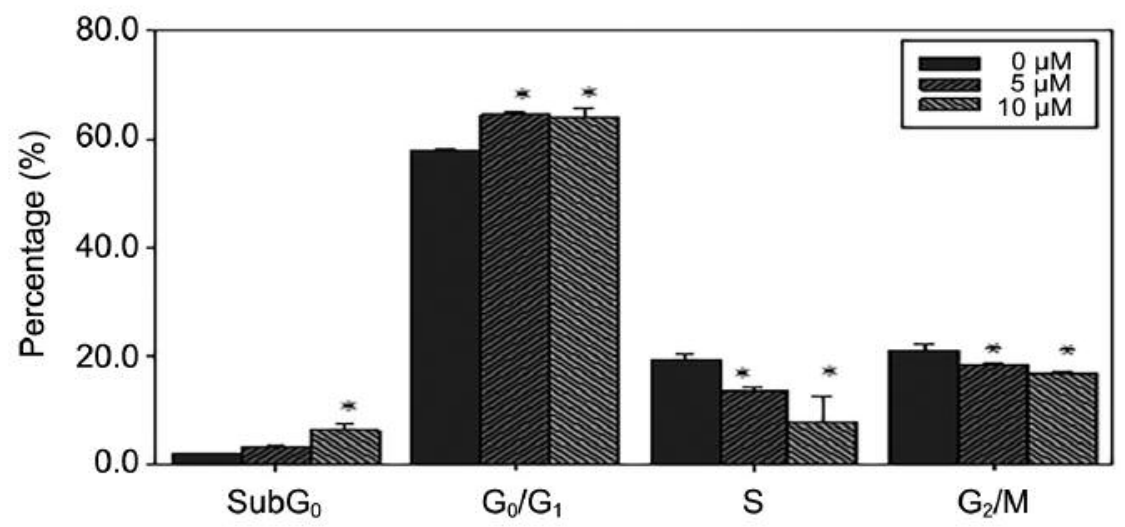

B HeLa

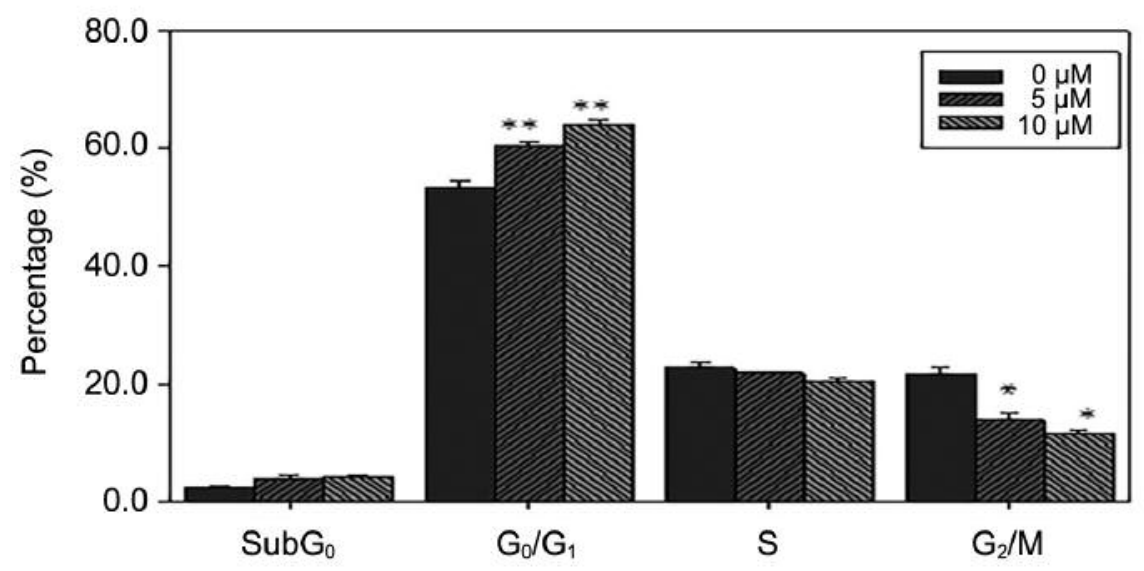

C $\mathrm{SiHa}$

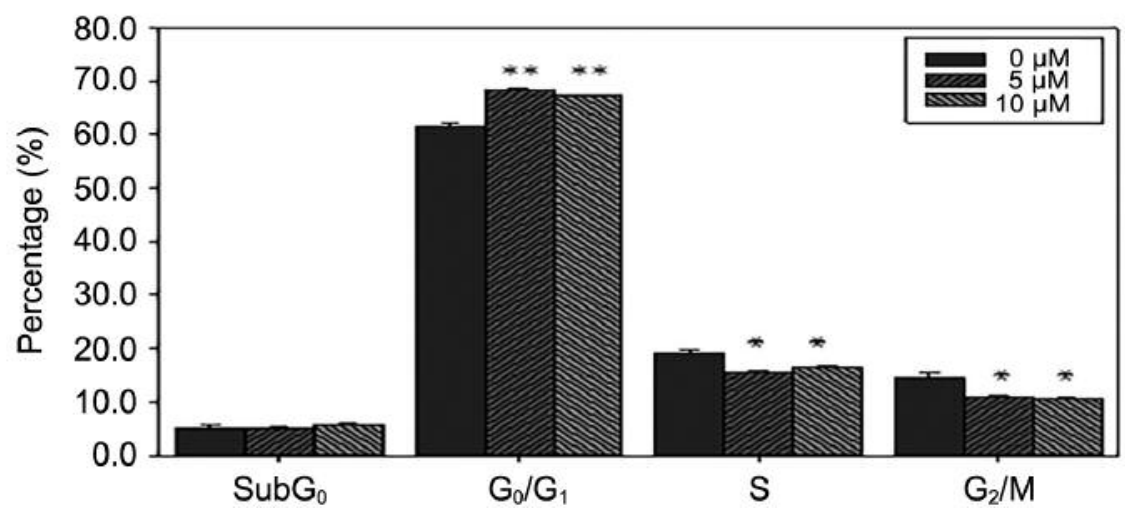

Figure 3. PTC209 induced $G_{0} / G_{1}$ arrest in the cervical cancer cell lines. C33A (A), HeLa (B), and SiHa $(\mathrm{C})$. Cells $\left(\right.$ about $\left.1 \times 10^{6}\right)$ were treated with PTC209 at indicated concentrations $(0,5$, and $10 \mu \mathrm{M})$ for $24 \mathrm{~h}$, and then fixed in $70 \%$ ethanol at $4^{\circ} \mathrm{C}$ overnight. After incubation with RNase A and propidium iodide, the cells were analyzed using the Attune NxT flow cytometer (Thermo Fisher Scientific). Each treatment was conducted in triplicate, and each sample was analyzed at least twice. Data were presented as mean $\pm S D$. For each cell line, the percentage of cells at a specific stage after treatment with PTC209 at indicated concentrations $(5 \mu M$ and $10 \mu M)$ was compared with that without PTC209 treatment $(0 \mu M)$ using two-sided Student's t-test. ${ }^{*} p<0.05 ; * * p<0.01 ; * * * p<0.001$. 
A C33A

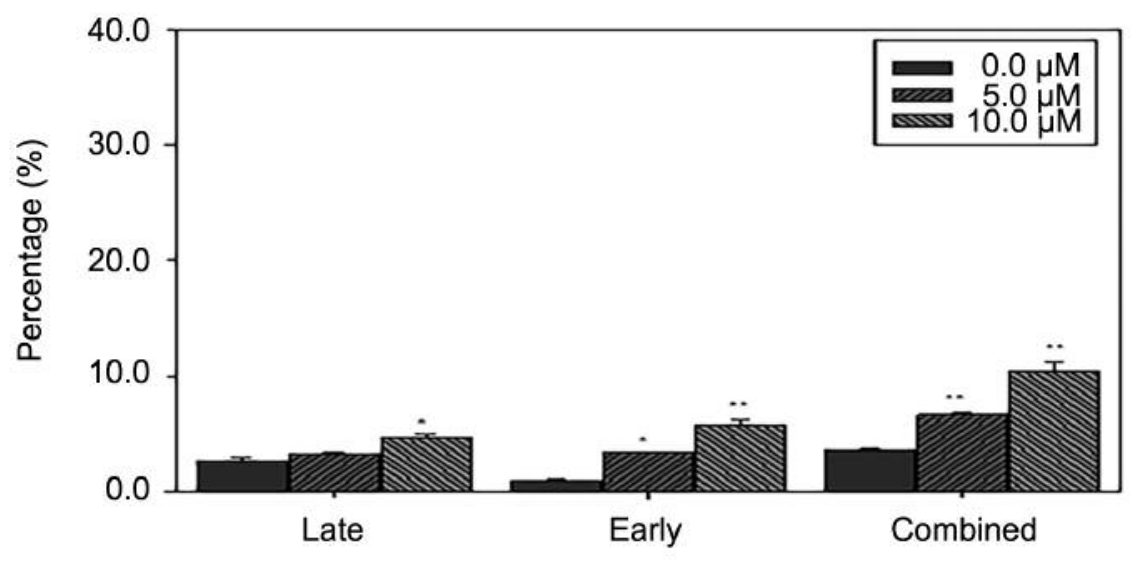

B HeLa

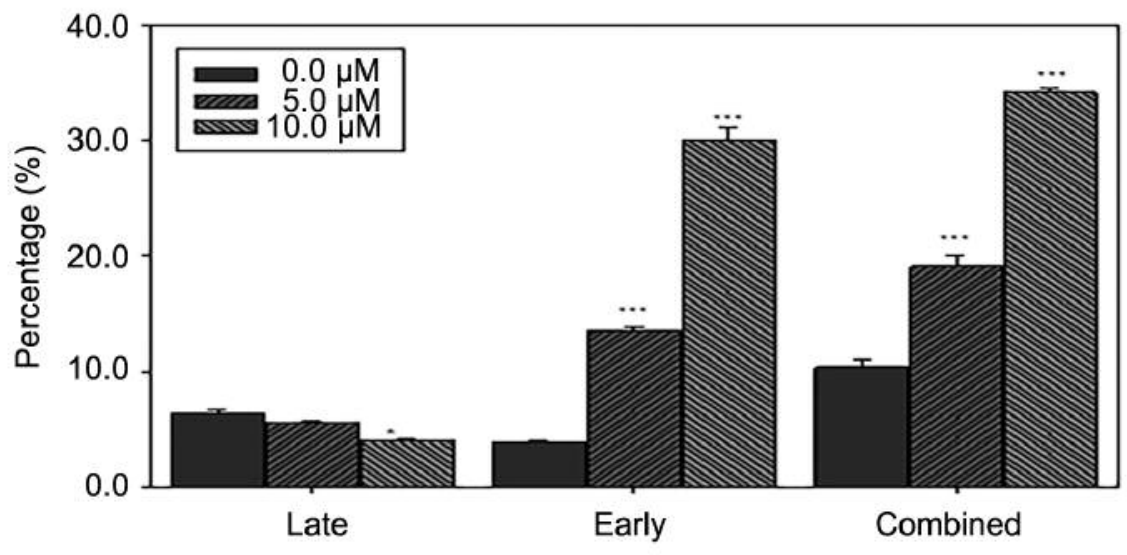

\section{C $\mathrm{SiHa}$}

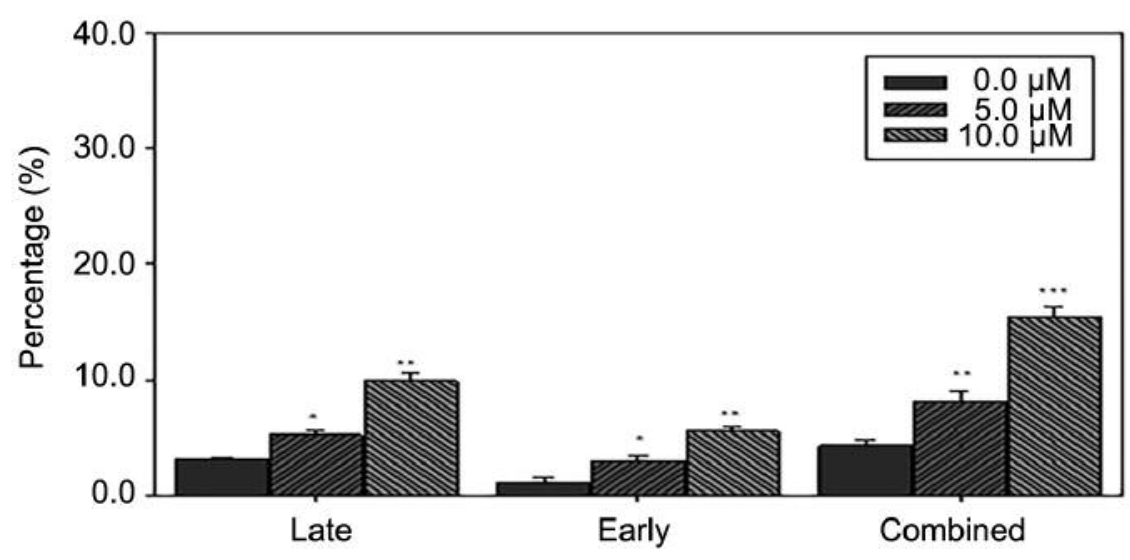

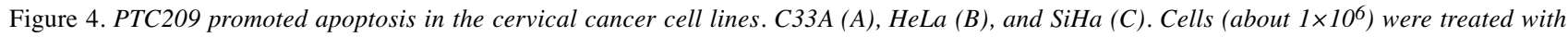
PTC209 at indicated concentrations $(0,5$, and $10 \mu \mathrm{M})$ for $24 \mathrm{~h}$, and stained with FITC Annexin-V/PI Apoptosis Detection kit I (BD Biosciences) following the manufacturer's instructions. Cells were analysed using the Attune NxT flow cytometer (Thermo Fisher Scientific) to measure apoptosis. Each treatment was conducted in triplicate, and each sample was analyzed at least twice. Data are presented as mean $\pm S D$. For each cell line, the percentage of cells at a specific stage after treatment with PTC209 at indicated concentrations $(5 \mu M$ and $10 \mu M)$ was compared with that without PTC209 treatment $(0 \mu M)$ using two-sided Student's t test. Early apoptosis, annexin $V^{+} / P I^{-}$; late apoptosis, annexin $V^{+} / P I^{+}$; combined, annexin $V^{+} / P I^{-}$and annexin $V^{+} / P I^{+} . * p<0.05 ; * * p<0.01 ; * * * p<0.001$. 
indicative of the potential of PTC209 as a novel chemotherapeutic agent in cancer therapy. This notion is further supported by recent studies $(17,18)$ demonstrating that upregulation of BMII is associated with chemoresistance and tumor recurrence in several cancer types, and PTC209mediated inhibition of BMI1 in primary or metastatic tumors may improve response to chemotherapeutic agents, such as carboplatin, doxo-rubicin, and castration .

Recent studies have also identified BMI1 as a key factor in the maintenance and/or self-renewal of many cancer stem cell types, including embryonic, neural, hematopoietic and prostate $(15,27-29,40,41)$. While BMI1 overexpression correlates with other stemness-related genes, such as SOX2, $K L F 4, N A N O G$, and gankyrin, in cervical, breast and head and neck cancers $(8,10,40,41)$, it has been demonstrated that the function of cancer-initiating cells (CICs) in colorectal cancer, breast cancer, and glioblastoma is dependent on BMI1 and PTC209-mediated downregulation of BMI1 inhibits these CICs to self-renew, resulting in the abrogation of their tumorigenic potential $(15,28,29,40)$.

Taken together, results from our laboratory and other groups reveal that BMI1 represents a novel target in both anti-cancer and anti-CSC therapies and it is valuable to further investigate the potentials of PTC209 as a single therapeutic agent or in combination with other chemotherapeutic agents in cervical cancer therapy $(30,42)$.

\section{Conflicts of Interest}

The Authors declare no conflicts of interest regarding this study.

\section{Authors' Contributions}

$\mathrm{JL}$ and MP designed the experiments, analysed the data, and wrote the manuscript. JL and ZV performed the experiments. All the Authors read and approved the final manuscript.

\section{References}

1 American Cancer Society. Cancer Facts \& Figures 2019. Atlanta: American Cancer Society, 2019.

2 Siegel RL, Miller KD and Jemal A: Cancer statistics, 2019. CA Cancer J Clin 69: 7-34, 2019. PMID: 30620402. DOI: 10.3 322/caac. 21551

3 Cohen PA, Jhingran A, Oaknin A and Denny L: Cervical cancer. Lancet 393: 169-182, 2019. PMID: 30638582. DOI: 10.1016/ s0140-6736(18)32470-x

4 Berman TA and Schiller JT: Human papillomavirus in cervical cancer and oropharyngeal cancer: one cause, two diseases. Cancer 123: 2221-2229, 2017. PMID: 28346680. DOI: 10.1002/ cncr.30588

5 Tong YQ, Liu B, Zheng HY, He YJ, Gu J, Li F and Li Y: Overexpression of BMI-1 is associated with poor prognosis in cervical cancer. Asia Pac J Clin Oncol 8: e55-62, 2012. PMID: 22898137. DOI: $10.1111 / \mathrm{j} .1743-7563.2012 .01564 . \mathrm{x}$
6 Chauhan SC, Jaggi M, Bell MC, Verma M and Kumar D: Epidemiology of human papilloma virus (HPV) in cervical mucosa. Methods Mol Biol 472: 439-456, 2009. PMID: 19109793. DOI: 10.1007/978-1-59745-416-2_22

7 Chen YC and Hunter DJ: Molecular epidemiology of cancer. CA Cancer J Clin 55: 45-54, 2005. PMID: 15661686. DOI: 10.3322/canjclin.55.1.45

$8 \mathrm{Xu} \mathrm{R}$, Chen L and Yang WT: Aberrantly elevated Bmi1 promotes cervical cancer tumorigenicity and tumor sphere formation via enhanced transcriptional regulation of Sox 2 genes. Oncol Rep 42: 688-696, 2019. PMID: 31173263. DOI: 10.3892/or.2019.7188

9 Janaki Ramaiah M and Vaishnave S: BMI1 and PTEN are key determinants of breast cancer therapy: a plausible therapeutic target in breast cancer. Gene 678: 302-311, 2018. PMID: 30096458. DOI: 10.1016/j.gene.2018.08.022

10 Poi MJ, Knobloch TJ, Sears MT, Uhrig LA, Warner BM, Weghorst $\mathrm{CM}$ and $\mathrm{Li} \mathrm{J}$ : Coordinated expression of cyclindependent kinase -4 and its regulators in human oral tumors. Anticancer Res 34: 3285-3292, 2014. PMID: 24982332.

11 Gray F, Cho HJ, Shukla S, He S, Harris A, Boytsov B, Jaremko L, Jaremko M, Demeler B, Lawlor ER, Grembecka J and Cierpicki T: BMI1 regulates PRC1 architecture and activity through homo- and hetero-oligomerization. Nat Commun 7: 13343, 2016. PMID: 27827373. DOI: $10.1038 /$ ncomms 13343

12 Zhu S, Zhao D, Yan L, Jiang W, Kim JS, Gu B, Liu Q, Wang R, Xia B, Zhao JC, Song G, Mi W, Wang RF, Shi X, Lam HM, Dong X, Yu J, Chen K and Cao Q: BMI1 regulates androgen receptor in prostate cancer independently of the polycomb repressive complex 1. Nat Commun 9: 500, 2018. PMID: 29402932. DOI: $10.1038 / \mathrm{s} 41467-018-02863-3$

13 Honig A, Weidler C, Hausler S, Krockenberger M, Buchholz S, Koster F, Segerer SE, Dietl J and Engel JB: Overexpression of polycomb protein VMI-1 in human specimens of breast, ovarian, endometrial and cervical cancer. Anticancer Res 30: 1559-1564, 2010. PMID: 20592341

14 Gavrilescu MM, Todosi Am, Anitei MG, Filip B and Scripcariu $\mathrm{V}$ : Expression of bmi-1 protein in cervical breast and ovarian cancer. Rev Med Chir Soc Med Nat Iasi 116: 1112-1117, 2012. PMID: 23700898.

15 Kreso A, van Galen P, Pedley NM, Lima-Fernandes E, Frelin C, Davis T, Cao L, Baiazitov R, Du W, Sydorenko N, Moon YC, Gibson L, Wang Y, Leung C, Iscove NN, Arrowsmith CH, Szentgyorgyi E, Gallinger S, Dick JE and O'Brien CA: Selfrenewal as a therapeutic target in human colorectal cancer. Nat Med 20: 29-36, 2014. PMID: 24292392. DOI: 10.1038/nm.3418

16 McGinty RK, Henrici RC and Tan S: Crystal structure of the PRC1 ubiquitylation module bound to the nucleosome. Nature 514: 591596, 2014. PMID: 25355358. DOI: 10.1038/nature13890

17 Yoo YA, Vatapalli R, Lysy B, Mok H, Desouki MM and Abdulkadir SA: The role of castration-resistant Bmi1+Sox2+ cells in driving recurrence in prostate cancer. J Natl Cancer Inst 111: 311-321, 2019. PMID: 30312426. DOI: 10.1093/jnci/djy 142

18 Shahi MH, York D, Gandour-Edwards R, Withers SS, Holt R and Rebhun RB: BMI1 is expressed in canine osteosarcoma and contributes to cell growth and chemotherapy resistance. PLoS One 10: e0131006, 2015. PMID: 26110620. DOI: 10.1371/journal. pone. 0131006

19 Li Z, Wang Y, Yuan C, Zhu Y, Qiu J, Zhang W, Qi B, Wu H, Ye $\mathrm{J}$, Jiang $\mathrm{H}$, Yanf $\mathrm{J}$ and Cheng $\mathrm{J}$ : Oncogenic roles of Bmil and its 
therapeutic inhibition by histone deacetylase inhibitor in tongue cancer. Lab Invest 94: 1431-1445, 2014. PMID: 25286028. DOI: 10.1038/labinvest.2014.123

20 Xu R, Yang WT and Zheng PS: Coexpression of B-lymphoma moloney murine leukemia virus insertion region-1 and sexdetermining region of $\mathrm{Y}$ chromosome-related high mobility group box-2 in cervical carcinogenesis. Hum Pathol 44: 208-217, 2013. PMID: 22863087. DOI: 10.1016/j.humpath.2012.02.020

21 Dimri M, Kang M and Dimri GP: A miR-200c/141-BMI1 autoregulatory loop regulates oncogenic activity of BMI in cancer cells. Oncotarget 7: 36220-36234, 2016. PMID: 27105 531. DOI: $10.18632 /$ oncotarget.8811

22 Dey A, Mustafi SB, Saha S, Kumar Dhar Dwivedi S, Mukherjee $\mathrm{P}$ and Bhattacharya R: Inhibition of BMI1 induces autophagymediated necroptosis. Autophagy 12: 659-670, 2016. PMID: 27050456. DOI: 10.1080/15548627.2016.1147670

23 Mourgues L, Imbert V, Nebout M, Colosetti P, Neffati Z, Lagadec P, Verhoeyen E, Peng C, Duprez E, Legros L, Rochet N, MaguerSatta V, Nicolini F-E, Mary D and Peyton JF: The BMI1 polycomb protein represses cyclin G2-induced autophage to support proliferation in chronic myeloid leukemia cells. Leukemia 29: 1993-2002, 2015. PMID: 25925206. DOI: 10.1038/leu.2015.112

24 Nishida Y, Maeda A, Chachad D, Ishizawa J, Qiu YH, Kornblau SM, Kimura S, Andreeff M and Kojima K: Preclinical activity of the novel B-cell-specific moloney murine leukemia virus integration site 1 inhibitor PTC-209 in acute myeloid leukemia: implications for leukemia therapy. Cancer Sci 106: 1705-1713, 2015. PMID: 26450753. DOI: 10.1111/cas.12833

25 Ohtaka M, Itoh M and Tohda S: BMI1 inhibitors down-regulate NOTCH signaling and suppress proliferation of acute leukemia cells. Anticancer Res 37: 6047-6053, 2017. PMID: 29061784. DOI: 10.21873 /anticanres.12052

26 Bolomsky A, Schlangen K, Schreiner W, Zojer N and Ludwig $\mathrm{H}$ : Targeting of BMI-1 with PTC-209 shows potent antimyeloma activity and impairs the tumor microenvironment. J Hematol Oncol 9: 17, 2016. PMID: 26935956. DOI: 10.1186/ s13045-016-0247-4

27 Darwish NHE, Sudha T, Godugu K, Elbaz O, Abdelghaffar HA, Hassan EEA and Mousa SA: Acute myeloid leukemia stem cell markers in prognosis and targeted therapy: potential impact of BMI-1, TIM-3, and CLL-1. Oncotarget 7: 57811-57820, 2016. PMID: 27506934. DOI: 10.18632/oncotarget.11063

28 Kong Y, Ai C, Dong F, Xia X, Zhao X, Yang C, Kang C, Zhou Y, Zhao Q, Sun X and Wu X: Targeting of BMI-1 with PTC-209 inhibits glioblastoma development. Cell Cycle 17: 1199-1211, 2018. PMID: 29886801. DOI: 10.1080/15384101.2018.1469872

29 Mayr C, Wagner A, Loeffelberger M, Bruckner D, Jakab M, Berr F, Fazio PD, Ocker M, Neureiter D, Pichler M and Kiesslich T: The BMI 1 inhibitor PTC-209 is a potential compound to halt cellular growth in biliary tract cancer cells. Oncotarget 7: 745758, 2016. PMID: 26623561. DOI: 10.18632/oncotarget.6378

30 Alzrigat M, Parraga AA, Majumder MM, Ma A, Jin J, Osterborg A, Nahi H, Nilsson K, Heckman CA, Oberg F, Kalushkova A and Jernberg-Wiklund $\mathrm{H}$ : The polycomb group protein BMI-1 inhibitor PTC-209 is a potent anti-myeloma agent alone or in combination with epigenetic inhibitors targeting EZH2 and the BET bromodomains. Oncotarget 8: 10371-10374, 2017. PMID: 29262596. DOI: 10.18632 oncotarget.21909

31 Xu J, Zhang Y, Xu J, Wang M, Liu G, Wang J, Zhao X, Qi Y, Shi J, Cheng K, Li Y, Qi S and Nie G: Reverse tumor stemness via orally targeted nanoparticles achieves efficient colon cancer treatment. Biomaterials 216: 119247, 2019. PMID: 31200145. DOI: $10.1016 /$ j.biomaterials.2019.119247

32 Poi MJ, Li J, Sborov DW, VanGundy Z, Cho YK, Lamprecht M, Pichiorri F, Phelps MA, Hofmeister CC. Polymorphism in ANRIL is associated with relapse in patients with multiple myeloma after autologous stem cell transplant. Mol Carcinog 56: 1722-1732, 2017. PMID: 28150872. DOI: 10.1002/mc.22626

33 Li J, Knobloch TJ, Poi MJ, Zhang Z, Davis AT, Muscarella P and Weghorst CM: Genetic alterations of RD(INK4/ARF) enhancer in human cancer cells. Mol Carcinog 53: 211-218, 2014. PMID: 23065809. DOI: $10.1002 / \mathrm{mc} .21965$

34 Persaud AK, Li J, Johnson JA, Seligson N, Sborov DW, Duah E, Cho YK, Wang D, Phelps MA, Hofmeister CC and Poi MJ: XRCC1-mediated DNA repair is associated with progressionfree survival of multiple myeloma patients after autologous stem cell transplant. Mol Carcinogenesis 58: 2327-2339, 2019. PMID: 31544312. DOI: $10.1002 / \mathrm{mc} .23121$

35 Chen S, Lv L, Zhan Z, Wang X, You Z, Luo X and You H Silencing of long noncoding RNA SRRM2-AS exerts suppressive effects on angiogenesis in nasopharyngeal carcinoma via activating MYLK-mediated cGMP-PKG signaling pathway. J Cell Physiol, 2019. PMID: 31742692. DOI: 10.1002/jcp.29382

36 Zheng W, Yao M, Fang M, Pan L, Wang L, Yang J, Dong Z and Yao D: Oncogenic Wnt3a: a candidate specific marker and novel molecular target for hepatocellular carcinoma. J Cancer 10: 5862-5873, 2019. PMID: 31737122. DOI: 10.7150/jca.31599

37 Fan T, Pi H, Li M, Ren Z, He Z, Zhu F, Tian L, Tu M, Xie J, Liu M, Li Y, Tan M, Li G, Qing W, Reiter RJ, Yu Z, Wu H, and Zhou Z: Inhibiting MT2-TFE3-dependent autophagy enhances melatonininduced apoptosis in tongue squamous cell carcinoma. J Pineal Res 64: e12457, 2018. PMID: 29149494. DOI: 10.1111/jpi.12457

$38 \mathrm{Li}$ J, Poi MJ and Tsai MD: Regulatory mechanisms of tumor suppressor P16INK4A and their relevance to cancer. Biochemistry 50: 5566-5582, 2011. PMID: 21619050. DOI: 10.1021/bi200642e

39 Chen F, Li Y, Wang L and Hu L: Knockdown of BMI-1 causes cell-cycle arrest and depresses p16 ${ }^{\text {INK4a }}$, HOXA9 and HOXC13 mRNA expression in HeLa cells. Med Oncol 28: 1201-1209, 2011. PMID: 20661663. DOI: 10.1007/s12032-010-9634-9.

40 Srinivasan M, Bharali DJ, Sudha T, Khedr M, Guest I, Sell S, Glinsky GV and Mousa SA: Dowregulation of Bmil in breast cancer stem cells suppresses tumor growth and proliferation. Oncotarget 8: 38731-38742. PMID: 28418883. DOI: 10.18632/ oncotarget.16317

41 Kaufhold S, Garban H and Bonavida B: Yin Yang 1 is associated with cancer stem cell transcription factors (SOX2, OCT4, BMI1) and clinical implication. J Exp Clin Cancer Res 35: 84, 2016. PMID: 27225481. DOI: 10.1186/s13046-016-0359-2

42 Elango R, Vishnubalaji R, Manikandan M, Binhamdan SI, Siyal A-A, Alshawakir YA, Alfayez M, Aldahmash A and Alajez NM: Concurrent targeting of BMI1 and CDK4/6 abrogates tumor growth in vitro and in vivo. Sci Rep 9: 13696, 2019. PMID: 31548560. DOI: $10.1038 / \mathrm{s} 41598-019-50140-0$

Received December 4, 2019

Revised December 10, 2019

Accepted December 12, 2019 